Proceedings of a Second Symposium on Scoliosis: Causation Edited by P. A. Zorab. Pp. 68, illustrated. Edinburgh and London: E. \& S. Livingstone, 1968. £1 10s.

To the orthopaedic trainee and indeed his tutors structural scoliosis is a complex problem in management. But cooperation with cardio-respiratory physicians, anaesthetists and others has done much to ease the heavy clinical burden. If the deformity is mechanically complex, its aetiology and pathogenesis are obscure and often baffling. However, when eminent anatomists, biochemists, physicians and orthopaedists convene to discuss these latter problems one may expect clarification. Most certainly these 'proceedings' do this and more, and should be read by all whose interests are in diseases of childhood. Scoliosis touches many systems.

The monograph reports on the experimental production of scoliosis in laboratory animals; the mechanical interpretations and explanations of the progression of the deformity; and the biochemical, metabolic and neurological diseases which are associated. Allusion is made to the genetic factors involved.

The contributors are lucid though not necessarily convincing. Photographs are of good quality; the tables in the text are simple and self-explanatory. Perhaps one could have expected something better than a paperback edition for a not inconsequential price, although this in no way detracts from the value that lies between the covers. This monograph is a useful supplement to standard orthopaedic texts and specialized works on scoliosis.

\section{Composition of Peripheral Nerves}

By Ian A. Boyd and Mary R. Davey. Pp. 57, illustrated. Edinburgh and London: E. \& S. Livingstone, 1968. £1 10s.

In their introduction the authors define their purpose, to report 'a study of the myelinated fibres forming group A in peripheral nerves in the cat'. Their title suggests a far wider purpose and is consequently very misleading.

In the interpretation of physiological experimentation there is, no doubt, room for various interpretations and many may disagree with some of the interpretations set out here. At the same time it is astonishing that this study entirely omits mention of the ultrastructure of myelinated nerve fibres and that the authors should believe that study of $7 \mu$ paraffin sections permits the measurement of myelin sheath thickness 'to the nearest $0.2 \mu$ '. Unless structure is better understood its relation to function becomes unreal.

\section{Physiology of Connective Tissue}

By Milos Chvapil. Pp. xiii +417 , illustrated. Prague: Czechoslovak Medical Press; London: Butterworth, 1968. $£ 510$ s.

To many clinicians and medical scientists the physiology and pathophysiology of connective tissue remain somewhat nebulous and difficult subjects. Indeed, the heterogeneity and ubiquity of connective tissue do make a coherent, comprehensive account of these subjects a formidable proposition, and it is not surprising that few authors have attempted such a feat.

In this volume Dr Chvapil has set out to present current knowledge of connective tissue from a functional viewpoint under the principal headings-mechanical, chemical and biological functions and their controlling mechanisms. Each of these aspects is dealt with in a separate chapter and there is, inevitably, a certain amount of dispersion of information on the one hand and overlap on the other.

At times the translation from the original language into English has produced unhappy results. Sentences such as'The ageing of macromolecules and especially proteins has in the past years been considered with the newly formed cross-linkages in active structure mainly owing to the works of...' and 'At the same time several processes take place concurrently'-are more common than one might have expected.

Nonetheless, considering the nature of the tasks before them, both the author and the translators have succeeded in producing a lively and stimulating work of interest to all who are engaged in connective tissue research or the unravelling of the properties of one or other of its components. There is an extensive bibliography.

\section{Vascular Diseases}

By M. J. Tsapogas, V. V. Kakkar and E. N. Gleave. Pp. 171, illustrated. London: H. K. Lewis, 1968. £2 10s.

Vascular disease is common but many doctors are uncertain how best to handle patients with diseased blood vessels. The authors of this short book state that they wrote it because they had often been asked by general practitioners, students and doctors preparing for higher degrees for a concise and practical book on vascular disease. The result of their efforts is somewhat disappointing.

The authors are surgeons with wide experience in the treatment of occlusive vascular disease and their attitude to investigation and treatment is understandably directed towards surgery and surgical techniques. There is almost no discussion of pathogenesis or prevention. There is no quantitative information about prognosis or the results of treatment either surgical or medical. The coronary circulation is not mentioned.

This book is unlikely to be of much use to anyone seeking a balanced introduction to the problem of vascular disease. Its bias towards a surgical approach might make it of greater value to someone reading for a higher degree in surgery but such a reader would probably require more information than is available in a book of 170 pages.

\section{Antimicrobial Agents and Chemotherapy-1967}

Edited by G. L. Новву. Proceedings of the Seventh Interscience Conference on Antimicrobial Agents and Chemotherapy, Chicago, Illinois, 25-27 October 1967. Pp. xiii + 779, illustrated. American Society for Microbiology. Edinburgh and London: E. \& S. Livingstone, 1968. £7.

This is the seventh annual publication of the proceedings of the conference held in the preceding autumn and contains over 120 short papers covering a wide range of subjects. Inevitably there is a certain unevenness in the quality of the contents but it contains much that is of interest for both clinician and microbiologist.

In the section on the regulation of clinical investigation various problems of over-regulation of clinical research are discussed and a plea is made for modification and relaxation of laws and regulations which are considerably more stringent than our own. It is interesting to note that the Federal Government increased its support for medical research to the massive sum of $\$ 1,181,000,000$ in 1967 .

Clinical studies receive rather less attention than their importance deserves. The views expressed at the round table on optimal duration of antibiotic therapy in severe bacterial infections are refreshing although no conclusions can be drawn from the scant evidence available. It was suggested that in most clinical situations a single antibiotic produces better results than combinations. This, and a similar statement that in bacterial meningitis a combination of bactericidal and bacteriostatic agents is undesirable, requires further elucidation.

Much of the latter part of the book deals with new antibiotics and synthetic antimicrobial agents and will be of interest mainly to the biochemist and research microbiologist. There is little to suggest that any of these new products is likely to be suitable for general use. If more time was devoted to determining the correct use of the antibiotics at present 